\title{
Estabilidade da Resistência de Capsicum spp. ao Oídio em Telado e Casa de Vegetação*
}

\author{
Milton L. Paz Lima ${ }^{1 * *}$, Carlos A. Lopes ${ }^{2 * *}$ \& Adalberto C. Café Filho ${ }^{1 * *}$ \\ ${ }^{1}$ Universidade de Brasília, Departamento de Fitopatologia, CEP 70910-900, Brasília, DF; '²mbrapa Hortaliças, \\ CEP 70359-970, Brasília, DF, e-mails: fitolima@unb.br; cafefilh@unb.br
}

(Aceito para publicação em 11/05/2004)

Autor para correspondência: Milton Luiz da Paz Lima

PAZ LIMA, M.L., LOPES, C.A. \& CAFÉ FILHO, A.C. Estabilidade da resistência de Capsicum spp. ao oídio em telado e casa de vegetação. Fitopatologia Brasileira 29:519-525. 2004.

\section{RESUMO}

Oídio (Oidiopsis taurica) é uma importante doença do pimentão (Capsicum annuum) e outras espécies de Capsicum. O objetivo deste trabalho foi identificar fontes de resistência no germoplasma de Capsicum spp. e relatar suas reações ao oídio em ambientes de telado e de casa de vegetação. Em telado, com inoculação artificial, testaram-se 104 genótipos de C. annuum, C. chinense, C. baccatum e C. frutescens. A avaliação foi repetida em canteiros de casa de vegetação com inoculação natural. Em telado, inoculou-se via atomização de $10^{4}$ conídios/ml e em casa de vegetação manteve-se como fonte de inóculo plantas de pimentão previamente infetadas. Os genótipos foram agrupados em cinco níveis de resistência, a partir de leituras periódicas de incidência, esporulação, severidade e intensidade total da doença, e da determinação das respectivas áreas abaixo das curvas de progresso da doença. Cerca de $77 \%$ dos genótipos avaliados em telado foram altamente (AS) ou moderadamente suscetíveis (MS); 8\% moderadamente resistentes (MR); $11 \%$ resistentes (R); e 4\% foram altamente resistentes (AR). Cerca de $72 \%$ dos genótipos avaliados em casa de vegetação foram AS ou MS; 11\% MR; 9\% R; e 8\% foram AR. Todos os genótipos classificados como AS tanto em telado quanto em casa de vegetação pertencem à espécie C. annuum. De modo geral, o ranking de resistência ao oídio permaneceu constante nos dois ambientes. Capsicum baccatum, C. frutescens e C. chinense apresentaram maior número de genótipos resistentes. Os principais genótipos AR foram CNPH 39, 161, 363 e 601 (C. baccatum); $\mathrm{CNPH}$ 579, 596 e 597 (C. frutescens); CNPH 55 (C. chinense); CNPH 280, 289, 434, 570 e 600 (C. chinense) е CNPH 1424 (C. annuum).

Palavras-chave adicionais: pimentão, pimenta, Oidiopsis taurica.
Stability of resistance of Capsicum spp. genotypes to powdery mildew in protected cropping

This work reports the resistance of Capsicum spp. genotypes to Oidiopsis taurica. Experiments were first conducted with artificial inoculation in pots in a screenhouse, with a set of 104 genotypes. A similar test was carried out with transplants in soil beds in a greenhouse, with 93 genotypes, selected from those previously tested in the screenhouse. In the screenhouse, plants were spray-inoculated with a conidial suspension of $10^{4} \mathrm{conidia} / \mathrm{ml}$. The source of inoculum in the greenhouse consisted of previously-infected sweet-pepper (Capsicum annuum) plants. Genotypes were separated into five resistance groups, following measurements of four disease variables: disease incidence, sporulation index, leaf severity index, and total disease intensity. In addition, the areas under disease progress curves

\section{INTRODUÇÃO}

Dentro do gênero Capsicum, C. annuum L. é a espécie mais cultivada e que apresenta maior variabilidade, sendo representada por pimentões e algumas pimentas. Outras espécies menos difundidas, Capsicum chinense H., C. frutescens L., C. baccatum L. e C. pubescens R. \& P. destacamse por serem fontes de resistência a pragas e doenças

\footnotetext{
*Parte da Dissertação de Mestrado do primeiro autor. Universidade de Brasília (2002). Apoio financeiro do CNPq e PRODETAB

**Bolsista CNPq
}

were determined for each variable. About $77 \%$ of the genotypes tested in the screenhouse were highly (HS) or moderately susceptible (MS); $8 \%$ moderately resistant (MR); $11 \%$ resistant (R); and $4 \%$ were highly resistant (HR). About $72 \%$ of the genotypes tested in the greenhouse were HS or MS; 11\% MR; 9\% R and 8\% HR. Capsicum annuum was the most susceptible species to $O$. taurica. Classification of most genotypes according to their resistance remained the same in the two experiments. Capsicum baccatum, C. frutescens and $C$. chinense had higher frequencies of resistant genotypes, and therefore, are considered to be good sources of resistance to the disease. The best sources of resistance (HR genotypes) were CNPH 39, 161, 363 and 601 (C. baccatum); CNPH 579, 596 and 597 (C. frutescens); CNPH 55 (C. annuum); CNPH 280, 289, 434, 570 and 600 (C. chinense) and CNPH 1424 (C. annuum).
(Reifschneider et al., 1998).

A ocorrência do oídio do pimentão foi relatada pela primeira vez no Brasil por Boiteux et al. (1994) como ocasionada por Leveillula taurica (Lév.) Arn. [anamorfo: Oidiopsis taurica (Arn) Salmon]. Embora a maioria dos autores refira-se ao agente causal do oídio em Capsicum spp. como L. taurica, a fase teleomórfica somente foi encontrada em alcachofra (Cynara scolymus L.), erva santa maria (Chenopodium ambrosioides L.) (Braun, 1980; Fernández, 1990), tomateiro (Lycopersicon esculentum Mill.) (Thomsom \& Jones, 1981) e Onobrychis viciifolia Scop. (Karakayama, 1998), nunca tendo sido relatada 
em pimentão. Em regiões de clima quente árido e semi-árido, os prejuízos estimados na cultura do tomateiro e pimentão podem ser elevados (Palti, 1988), com perdas estimadas em 30-40\% na região do Mediterrâneo (Palti, 1971). Não há estimativas de perdas causadas por oídio em pimentão no Brasil, embora a doença seja muito prevalente em cultivo protegido, obrigando a adoção de várias medidas de controle. Além do amarelecimento avançando para necroses em alguns genótipos de Capsicum spp. (Paz Lima \& Café Filho, 2001), outro sintoma que afeta grandemente a produção de pimentão em cultivos protegidos é a abscisão foliar (Reuveni et al., 1974). Desfolha severa é um dos principais sintomas observados em plantas infetadas.

A linhagem africana H3 (linhagem etíope), identificada pela primeira vez por Daubèze et al. (1989), é a base do melhoramento de pimentão visando resistência ao oídio e é, até hoje, utilizada nos programas de melhoramento e em estudos da resistência. A resistência do material suscetível ('Vânia') cruzado com a linhagem H3 é estável na França (Daubèze et al., 1989), em Israel (Shifriss et al., 1992) e na Tunísia (Allagui, 1993). Este material também se comportou como resistente no Brasil (Souza \& Café Filho, 2003).

Daubèze et al. (1995) ao cruzarem progênies de $C$. annuum, androgeneticamente haplodiplóides- $\mathrm{H}^{\mathrm{R}}$, com híbridos F1-Vânia ${ }^{\text {s }}$ desenvolveram a linhagem HV imune a $O$. taurica, sendo este o primeiro relato de um genótipo de $C$. annuum imune ao oídio. Posteriormente, o controle genético da resistência a $O$. taurica no híbrido 'HV-12' foi estudado por Shifriss et al. (1992), que comprovaram que a resistência é controlada por três pares de genes. Segundo Daubèze et al. (1995), dois ou três fatores genéticos com efeito de dominância parcial ou aditiva operam para conferir resistência a $O$. taurica. Entretanto, o efeito de genes adicionais também é detectado quando ocorrem epidemias fracas, totalizando cinco fatores genéticos que atuam com efeito aditivo. A modulação da reação de resistência/susceptibilidade em função do ambiente é uma resposta quantitativa, característica de componentes de resistência horizontal sensu Van der Plank (1963).

A baixa umidade do ar favorece o desenvolvimento de oídio (Reuveni \& Rotem, 1973; Palti, 1988) e tal condição explica as severas epidemias em Capsicum spp. em cultivo protegido durante a época seca. Recentemente vem se observando um grande aumento dos oídios em várias hospedeiras [tomateiro, batata (Solanum tuberosum L.), berinjela (S. melongena L.), jiló (S. gilo Raddi)], e algumas das possíveis causas desse aumento da importância dos oídios em Solanaceae foram discutidos recentemente (Café Filho et al., 2001).

Genótipos de pimentão foram avaliados para resistência ao oídio causado por O. taurica em vários países (Kounovski et al., 1985; Bidari et al., 1985; Anand et al., 1987; Shifriss et al., 1992; Muneem et al., 1994; Daubèze et al., 1995). No Brasil, Souza \& Café Filho (2003) e Paz Lima \& Café Filho (2001) relataram a reação de genótipos indicando um continuum quanto à resistência, variando desde "imunes" até altamente suscetíveis (Café Filho et al., 2001). Este trabalho teve como objetivo avaliar a reação de genótipos de Capsicum a $O$. taurica em condições de telado e de casa de vegetação como subsídio ao melhoramento genético visando resistência ao oídio.

\section{MATERIALEMÉTODOS}

Dois experimentos foram realizados visando comparar a reação de genótipos de Capsicum spp. a O. taurica em diferentes condições ambientais. O primeiro teste foi conduzido com 104 genótipos cultivados em vasos em telado e o segundo com 93 genótipos, selecionados dentre os anteriormente testados, cultivados em solo de casa de vegetação climatizada.

\section{Avaliação em telado}

A avaliação em telado foi conduzida seguindo delineamento experimental inteiramente casualizado com cinco repetições. Foram analisados 83 genótipos de C. annuum; 11 de $C$. chinense; seis de $C$. baccatum e quatro de $C$. frutescens. Cinco mudas de cada genótipo foram transplantadas aos 30 dias após a semeadura para vasos de $2 \mathrm{l}$, mantendo-se uma planta por vaso, que constituiu a parcela experimental. Durante a condução do experimento não foram realizadas pulverizações para o controle de pragas e doenças.

Procedeu-se à inoculação do patógeno via atomização de suspensão de conídios ( $10^{4}$ conídios $/ \mathrm{ml}$ ) em plantas com dez a 12 folhas. $\mathrm{O}$ isolado de $O$. taurica foi coletado em folhas de pimentão 'Magali' no Núcleo Rural de Taquara/DF, e identificado de acordo com Molot \& Lecoq (1986). As avaliações iniciaram-se aos 16 dias após a inoculação com intervalos de sete dias, totalizando seis avaliações. Foram feitas leituras periódicas de três variáveis epidemiológicas primárias e uma secundária. A incidência da doença (\%) foi medida pelo número de folhas com sintoma da doença/número total de folhas. Através de escalas modificadas de Daubèze et al. (1995) mediram-se o Índice de esporulação (SPOR, 0-5) baseado na área foliar com esporulação (Tabela 1) e o Índice de folhagem infetada (PropFo, 0-5) baseada na porcentagem de folhas que apresentam sinais do patógeno (Tabela 2), e a Intensidade da doença que é um índice secundário, composto da soma dos dois componentes anteriores (Id-notas $=$ SPOR + PropFo) resultando numa escala de 0-10. A criação da variável secundária (Id-notas) foi utilizada a fim de mostrar um valor único que expressa a soma das capacidades separadas de um genótipo (hospedeiro) de reduzir a esporulação do patógeno (SPOR), assim como a capacidade de resistir à infecção da folhagem (PropFol).

As áreas abaixo da curva de progresso da doença foram estimadas para as quatro variáveis $\left(\mathrm{AACPD}_{\%}, \mathrm{AACPD}_{\mathrm{SPOR}}\right.$, $\mathrm{AACPD}_{\text {PropFo }}$ e $\mathrm{AACPD}_{\mathrm{Id}}$ ), de acordo com metodologia de Shaner \& Finney (1977). Os valores das AACPD foram utilizados para separação em grupos através de duas técnicas de análise multivariada, a análise de componentes principais, utilizando o procedimento de Tocher (programa GENES), e a análise de agrupamento ('cluster' - programa STATISTICA), utilizando como medida de similaridade a distância euclidiana 
Estabilidade da resistência de Capsicum spp. ao oídio em...

TABELA 1 - Escala de notas do índice de esporulação (SPOR, 0-5), baseada na área foliar esporulada (modificada de Daubèze et al., 1995)

\begin{tabular}{ll}
\hline \hline Nota & Característica \\
\hline $\mathbf{0}$ & Sem sinal do patógeno (sem sintoma); \\
$\mathbf{1}$ & Manchas cloróticas restritas, sem esporulação; \\
$\mathbf{2}$ & Sítios de esporulação isolados, cobrindo menos que 25\% da área \\
& foliar; \\
$\mathbf{3}$ & Esporulação cobrindo de 25 a $50 \%$ da área foliar infetada; \\
$\mathbf{4}$ & Esporulações coalescentes, cobrindo de 51 a $75 \%$ da área foliar; \\
$\mathbf{5}$ & Acima de 75\% da superficie foliar com densa esporulação \\
\hline
\end{tabular}

TABELA 2 - Escala de notas do índice de folhagem infetada (PropFo, $0-5)$, baseada na porcentagem de folhas que apresentam sinais do patógeno (modificada de Daubèze et al., 1995)

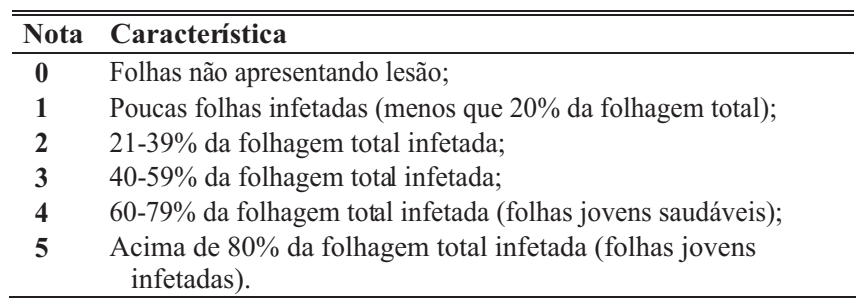

(Zar, 1998). Aos 95 dias após o transplante, avaliou-se a porcentagem de abscisão foliar, obtida a partir da razão do número de áxis foliares sem folhas pelo número de áxis totais nas cinco repetições utilizando a seguinte escala: classe $1=10$ $20 \%$ de queda de folhas; classe $2=21-40 \%$; classe $3=41-60 \%$; classe $4=61-80 \%$; classe $5=81-100 \%$.

\section{Avaliação em casa de vegetação}

O experimento foi conduzido em canteiros no interior de casa de vegetação climatizada, com área total de 390 m², com cobertura plástica ('Van der Hoeven') seguindo o delineamento inteiramente casualizado com cinco repetições e parcelas experimentais contendo duas plantas. Foram analisados 93 genótipos de Capsicum spp., basicamente os mesmos previamente avaliados em telado protegido, sendo 76 de $C$. annuum, oito de $C$. chinense, cinco de C. baccatum e quatro de $C$. frutescens. As mudas foram transplantadas para canteiros de $0,80 \mathrm{~m}$ de largura aos 30 dias após a semeadura. Durante a condução do experimento não foi realizada nenhuma pulverização. Nas extremidades da casa de vegetação foram transplantadas mudas de pimentão 'Magali', classificado previamente como altamente suscetível ao oídio (Souza \& Café Filho, 2003), que foram inoculadas via atomização $\left(10^{4}\right.$ conídios/ $\mathrm{ml}$ ), para servir de fonte de inóculo para os demais genótipos aos 60 dias antes do plantio dos materiais a serem testados. Foram monitoradas a temperatura e a umidade dentro do dossel da planta a $50 \mathrm{~cm}$ da superfície do solo, utilizando o equipamento de medição automática METOS (Pessl Instruments), com intervalos de 15 min.

Procederam-se leituras periódicas de incidência e severidade de doença, compostas por três variáveis primárias (Inc-\%, SPOR e PropFo) e uma secundária (Id-notas), utilizando- se os mesmos procedimentos da avaliação em telado. As avaliações iniciaram-se aos 13 dias após o transplante, com intervalos de dez dias, sendo feitas quatro avaliações. Os dados obtidos serviram para determinar as áreas abaixo da curva de progresso da doença, por $\mathrm{AACPD}_{\%}, \mathrm{AACPD}_{\mathrm{SPOR}}$, $\mathrm{AACPD}_{\text {PropFo }}$ e $\mathrm{AACPD}_{\mathrm{Id}}$. As AACPD's foram submetidas a análise de agrupamento do tipo 'cluster' utilizando como medida de similaridade a distância euclidiana utilizando o programa STATISTICA for windows, versão 5.0.

\section{RESULTADOSE DISCUSSÃO}

\section{Avaliação em telado}

Cerca de 68\% dos genótipos foram considerados altamente suscetíveis (AS); 9\% moderadamente suscetíveis (MS); 8\% moderadamente resistentes (MR); 11\% resistentes (R) e 4\% foram altamente resistentes (AR) (Tabelas 3, 4).

Todos os 71 genótipos classificados como AS pertencem à espécie $C$. annuum, reunindo mais de $85 \%$ dos $C$. annuum estudados. Dos genótipos de C. annuum restantes, cerca de $10 \%$ foram MS, um genótipo foi MR, dois foram R e apenas um genótipo foi considerado AR (CNPH 1424). Dentre os sete genótipos de $C$. baccatum, três foram $\mathrm{AR}$, três foram $\mathrm{R}$ e apenas um foi MR; $C$. chinense teve seis genótipos $\mathrm{R}$ e cinco genótipos MR. Nenhum genótipo de $C$. baccatum ou de $C$. chinense foi classificado como MS ou AS. Capsicum frutescens apresentou dois genótipos R, um genótipo MR e um genótipo MS. Os genótipos classificados nas classes AR e R podem servir como fontes de resistência em programas melhoramento. Os quatro genótipos mais resistentes foram CNPH 1424 (C. annuит) е CNPH 363, 161 e 39 (C. baccatum). Outras fontes de resistência foram recentemente identificadas por Souza \& Café Filho (2003).

Houve forte correlação positiva (amplitude de $\mathrm{r}^{* *}=$ 0,826 a 0,973) entre as variáveis epidemiológicas (Inc-\%, SPOR, PropFo e Id-notas), ou seja, em todas as combinações existe forte relação de dependência entre as mesmas. Em genótipos resistentes (AR, R e MR) ficou caracterizado sintoma de folhas apresentando manchas cloróticas bem delimitadas que, com o progresso da doença, evoluem para necroses (Figura 1C), não havendo perda de folhas. Em genótipos suscetíveis (AR e MS) ficou caracterizado o amarelecimento generalizado e abundante esporulação fúngica na folha atacada (Figura 1B) com a agravante de que em alguns genótipos como 'Magali' ocorreu intensa abscisão foliar (Figura 1A). Os sintomas ilustrados (Figura 1) variam bastante entre os genótipos, e nem sempre os genótipos suscetíveis apresentam alta quantidade de esporulação. Assim, a área foliar com esporulação e a porcentagem de folhagem que apresenta sinais do patógeno são variáveis que em alguns casos apresentamse como independentes (genótipos AR, R e S) e, em outros casos, dependentes (MR, MS). A formação de ciclos secundários da doença ficou muito mais evidenciada nos genótipos suscetíveis, pois nas resistentes raramente notouse uma esporulação abundante nas áreas de tecido delimitado (Paz Lima \& Café Filho, 2001). A esporulação, portanto, é pouco 
TABELA 3 - Classificação em grupos de resistência de genótipos de Capsicum spp. infetados por Oidiopsis taurica avaliados em vasos em telado protegido e em canteiros em casa de vegetação

\begin{tabular}{|c|c|c|c|c|c|c|c|c|c|}
\hline \multirow{2}{*}{$\begin{array}{l}\text { Grupo }^{(a)} \text { ou } \\
\mathbf{N}^{0} . \text { CNPH }\end{array}$} & \multirow{2}{*}{ Nome comum } & \multirow{2}{*}{ Espécie } & \multicolumn{2}{|c|}{ Grupos de Resistência ${ }^{(\mathrm{b})}$} & \multirow{2}{*}{$\begin{array}{l}\text { Grupo }^{(a)} \text { ou } \\
\mathbf{N}^{0} \text {. CNPH }\end{array}$} & \multirow{2}{*}{ Nome comum } & \multirow{2}{*}{ Espécie } & \multicolumn{2}{|c|}{ Grupos de Resistência $^{(b)}$} \\
\hline & & & Telado & Casa Vegetaçao & & & & Telado & Casa Vegetação \\
\hline \multirow[t]{2}{*}{23} & BGH 2678 & Capsicum & $\mathrm{AS}$ & AS & 3339 & Margarita & C. annuиm & MS & $\overline{A S}$ \\
\hline & & annuum & & & 3340 & Nathalie & C. annuиm & AS & MS \\
\hline 25 & BGH 3032 & C. annuum & AS & AS & 3342 & Hyb. Pepper Firenza & C. annuum & MS & MS \\
\hline 40 & Takanotsume & C. annuum & AS & AS & $3343^{(\mathrm{c})}$ & Hyb. Pepper RPP 3386 & C. annuum & AS & - \\
\hline 43 & Niko-Nanban & C. annuum & AS & AS & 3344 & Hyb. Pepper Pep 1226 V & VP C. annuum & AS & MR \\
\hline 44 & Shin-Santaka & C. annuum & AS & MS & Melh. & $4090-\mathrm{P}$ & C. annuum & AS & MR \\
\hline 64 & Long Red Cayenne & C. annuum & AS & AS & Melh. & 4109-P & C. annuиm & AS & MR \\
\hline 144 & MC-5 & C. annuum & $\mathrm{R}$ & AS & Melh. & 4504-P & C. annuum & AS & MS \\
\hline 146 & PM-217 & C. апnиит & AS & AS & Melh. & 4505-P & C. annuum & AS & AS \\
\hline 149 & PM-701 & C. annuum & AS & AS & Melh. & 88-P & C. annuum & AS & AS \\
\hline 181 & Pimentão italiano & C. annuит & MR & MS & Melh. & 4665-P & C. annuum & AS & MR \\
\hline 183 & PI 187331 & C. annuит & AS & MR & Melh. & 4237-P & C. annuum & AS & AS \\
\hline 192 & Magda & C. annuum & AS & AS & Melh. & $4240-\mathrm{P}$ & C. annuum & AS & AS \\
\hline 194 & Cascadura & C. annuит & MS & AS & Melh. & 4241-P & C. annuum & AS & AS \\
\hline 199 & Ambato & C. annuum & AS & MS & Melh. & 4242-P & C. annuum & $\mathrm{AS}$ & AS \\
\hline 292 & Bell Boy & C. annuum & AS & $\mathrm{R}$ & Melh. & 4244-P & C. апnuит & AS & AS \\
\hline 433 & Sweet Pepper Blue Star & C. annuит & MR & AS & Melh. & 4249-P & C. annuum & AS & AS \\
\hline 580 & Lito & C. annuum & AS & AS & Melh. & 4251-P & C. annuum & AS & AS \\
\hline 583 & Herpa & C. annuum & AS & MS & Melh. & Tico & C. annuum & $\mathrm{AS}$ & MR \\
\hline 593 & PI 1750 & C. annuит & AS & MR & Melh. & 4506-P & C. annuum & AS & AS \\
\hline $594^{(\mathrm{c})}$ & Bellamy (Paprika) & C. annuum & AS & - & Melh. & 4507-P & C. апnuиm & AS & MS \\
\hline 645 & Gigante amarelo & C. annuum & AS & AS & Hib.Com. & Magnata & C. annuum & AS & AS \\
\hline 676 & PI 135873 & C. annuum & AS & AS & Hib.Com. & Magali & C. annuum & AS & AS \\
\hline 677 & PI 138562 & C. annuum & AS & AS & Hib.Com. & All Big & C. апnuит & AS & AS \\
\hline 683 & PI 164471 & C. апnиит & AS & AS & Hib.Com. & Yolo Wonder & C. апnuиm & AS & AS \\
\hline 684 & PI 164557 & C. annuum & AS & AS & Hib.Com. & Dagmar & C. annuum & AS & AS \\
\hline 688 & PI 167361 & C. annuum & AS & AS & Hib.Com. & Cascadura Ikeda & C. annuum & AS & AS \\
\hline 691 & PI 169122 & C. annuum & MS & MS & Hib.Com. ${ }^{(c)}$ & Reinger & C. annuum & $\mathrm{AS}$ & - \\
\hline 693 & PI 169134 & C. апnиит & AS & AS & Hib.Com. & Elisa & C. апnuиm & AS & AS \\
\hline 697 & PI177301 & C. annuит & AS & MS & 35 & Shishito & C. annuит & MS & AS \\
\hline 709 & PI 201241 & C. annuит & AS & $\mathrm{AS}$ & 39 & Nélio & C. baccatum & $\mathrm{AR}$ & $\mathrm{R}$ \\
\hline 723 & PI 268104 & C. annuum & AS & AS & 161 & Pimenta dedo de moça & C.baccatum & $\mathrm{AR}$ & $\mathrm{R}$ \\
\hline $726^{(\mathrm{c})}$ & PI 281341 & C. annuит & AS & - & $362^{(\mathrm{c})}$ & Pimenta Mogi das Cruzes & C. baccatum & $\mathrm{R}$ & - \\
\hline 727 & PI 281383 & C. annuит & AS & AS & $363^{(\mathrm{c})}$ & Pimenta Mogi das Cruzes & C. baccatum & $\mathrm{AR}$ & - \\
\hline 732 & PI 342946 & C. annuum & AS & AS & 601 & Pimenta EEA & C. baccatum & $\mathrm{R}$ & $\mathrm{AR}$ \\
\hline 738 & PI 368400 & C. annuum & AS & AS & 672 & Pimenta & C. baccatum & $\mathrm{R}$ & MR \\
\hline 742 & PI 368442 & C. annuum & AS & AS & 1364 & Dedo de moça & C. baccatum & MR & MR \\
\hline 746 & PI 370373 & C. апnиит & AS & AS & $280^{(\mathrm{c})}$ & Pimenta de cheiro & C. chinense & $\mathrm{R}$ & - \\
\hline 748 & PI 379163 & C. annuum & MS & AS & 289 & Pimenta olho de ganso & C. chinense & $\mathrm{R}$ & $\mathrm{R}$ \\
\hline 776 & WIR 1546 & C. annuит & AS & AS & 55 & Pimenta de cheiro & C. chinense & $\mathrm{R}$ & $\mathrm{R}$ \\
\hline 777 & WIR 2370 & C. annuит & $\mathrm{R}$ & AS & 434 & Pimenta peixe boi & C. chinense & $\mathrm{R}$ & $\mathrm{AR}$ \\
\hline 994 & Peperone Como di toro & C. annuum & AS & MS & 436 & Pimenta do Maranhão & C. chinense & MR & $\mathrm{R}$ \\
\hline $1387^{(\mathrm{c})}$ & Páprica & C. annuum & AS & - & 503 & Pimenta do Maranhão & C. chinense & MR & $\mathrm{R}$ \\
\hline 1424 & Pimenta & C. annuum & $\mathrm{AR}$ & $\mathrm{AR}$ & $570^{(\mathrm{c})}$ & Pimenta picante & C. chinense & $\mathrm{R}$ & - \\
\hline $2688^{(\mathrm{c})}$ & Cherry Pepper Mild & C. аппиит & AS & - & 573 & Pimenta picante & C. chinense & MR & $\mathrm{R}$ \\
\hline 2731 & Amarelo de São Paulo & C. апnuит & AS & AS & $578^{(\mathrm{c})}$ & Pimenta Murupi & C. chinense & MR & - \\
\hline 2764 & Hot Poken F2 & C. annuиm & AS & AS & 600 & Pimenta de Cheiro & C. chinense & $\mathrm{R}$ & MR \\
\hline 3294 & Jalapeño 4130 & C. annuит & AS & AS & 670 & Pimenta & C. chinense & MR & MR \\
\hline 3295 & Jalapeño 4139 & C. annuит & AS & $\mathrm{AS}$ & 579 & Pimenta Doce & C. frutescens & MR & $\mathrm{AR}$ \\
\hline 3296 & Nathalie & C. annuum & AS & MS & 595 & Pimenta malagueta & C. frutescens & MS & $\mathrm{AR}$ \\
\hline 3297 & Myr 10 & C. annuит & AS & MR & 596 & Pimenta malagueta & C. frutescens & $\mathrm{R}$ & $\mathrm{AR}$ \\
\hline 3298 & Myr 29 & C. annuum & AS & MS & 597 & Pimenta malagueta grande & de frutescens & $\mathrm{R}$ & $\mathrm{AR}$ \\
\hline 3299 & Jalapeño 4129 & C. annuum & AS & MS & & & & & \\
\hline
\end{tabular}

(a) Grupo de genótipos (Melh. - material de melhoramento; Híbr.Com. - híbridos comerciais); (b) Grupo de Resistência (AR - altamente resistente, R resistente, MR - moderadamente resistente, MS - moderadamente suscetível, AS - altamente suscetível); ( - ) genótipo não avaliado; (c) genótipos avaliados somente em telado

abundante em genótipos resistentes, e, desta forma, há reduzido número de ciclos secundários da doença, ao contrário dos genótipos suscetíveis. Conseqüentemente, há limitação da severidade da epidemia. Outro fator determinante da severidade das epidemias do oídio de pimentão é a duração do período de latência, que aumenta nos genótipos resistentes 
TABELA 4 - Porcentagem de genótipos de Capsicum spp. segundo grupos de resistência à Oidiopsis taurica em telado e em casa de vegetação

\begin{tabular}{|c|c|c|}
\hline \multirow{2}{*}{ Grupos de resistência } & \multicolumn{2}{|c|}{ Distribuição genótipos (\%) } \\
\hline & Telado & Casa de vegetação \\
\hline Altamente resistente (AR) ${ }^{(a)}$ & 4,0 & 8,0 \\
\hline Resistente (R) ${ }^{\text {(a) }}$ & 11,5 & 9,0 \\
\hline Moderadamente resistente (MR) & 7,8 & 11,0 \\
\hline Moderadamente suscetível (MS) & 8,7 & 16,0 \\
\hline Altamente suscetível (AS) & 68,0 & 56,0 \\
\hline
\end{tabular}

(a) Genótipos classificados nos grupos de resistência em pelo menos um ambiente avaliado: AR-CNPH 39, 161, 363, 601, 579, 596, 597, 55, 280, 289, 434, 570, 600, 1424. R-CNPH 39, 55, 144, 161, 280, 289, 292, 362, 434, 436, 503, 570, 573, 596, 597, 601, 672, 777,

\section{(Souza \& Café Filho, 2003).}

Para $80 \%$ do germoplasma testado, a porcentagem de abscisão foliar devida ao oídio aos 95 dias após o transplante foi de 0 a $20 \%$. Dos genótipos restantes, $14 \%$ apresentaram valores de $21-40 \%$, $2 \%$ valores de $41-60 \%$ e $4 \%$ tiveram $61-80 \%$ de abscisão. A porcentagem de abscisão foliar variou tanto em função do ataque do patógeno quanto das características fenológicas intrínsecas da hospedeira. As espécies $C$. frutescens, C. baccatum e C. chinense apresentaram como característica fenológica uma elevada perda de folhas principalmente no início do período de frutificação, mesmo com baixa susceptibilidade ao oídio. Os genótipos moderadamente resistentes apresentaram freqüências de abscisão distribuídas na amplitude de $0-100 \%$. Neste estudo houve baixa correlação negativa da abscisão foliar com grupos de resistência $\left(r^{* *}=-0,408\right)$. Neste aspecto esperava-se que os genótipos AS apresentassem maior porcentagem de abscisão foliar conforme relatado por Reuveni et al. (1974) e Allagui et al. (1995). As diferenças entre os nossos resultados e os estudos anteriores podem ser creditadas primariamente aos diferentes genótipos estudados. Sugere-se que, nas espécies C. baccatum, $C$. chinense e $C$. frutescens, a abscisão de folhas é relacionada primeiramente a características fenológicas da planta, e secundariamente ao estresse ocasionado pelo patógeno.

Normalmente o início do aparecimento dos primeiros sintomas de oídio em Capsicum spp. se dá no estádio de florescimento (Café Filho et al., 2001). Para testar diretamente esta hipótese correlacionou-se o número de dias após o transplante até o florescimento com os graus de resistência (15 = AR, R, MR, MS, AS ) verificados nos 104 genótipos testados em telado. Os resultados revelaram baixa, porém significativa, correlação $\left(\mathrm{r}^{* *}=-0,452\right)$, entre o grau de resistência e o número de dias que as plantas levaram para florescer. Isto indica que geralmente quanto mais tarde ocorrer o florescimento mais resistente será a reação de um determinado genótipo, sendo a precocidade ao florescimento em pimentão um fator importante a ser analisado como indicativo de resistência ou susceptibilidade ao oídio.

A desfolha e a redução da área foliar sadia estudadas por Reuveni \& Rotem (1973) resultam em redução da produção

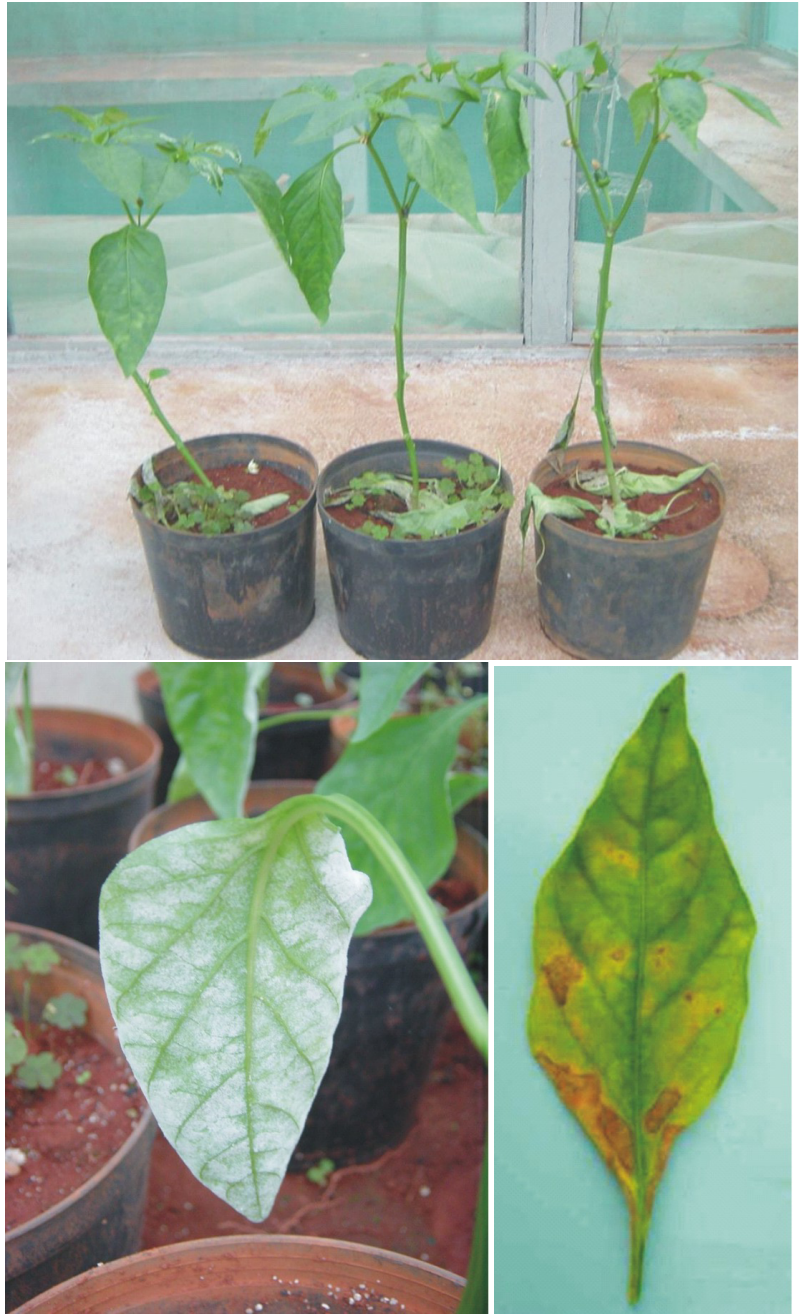

FIG. 1 - Sintomatologia em folhas de pimentão (Capsicum annuum) infetadas por O. taurica. A. Abscisão (cv. Magali), B. esporulação abundante em folhas de genótipo altamente suscetível (cv. Magali), C. folha clorótica e necrosada de genótipo resistente ('Shishito’).

de frutos. Nos 104 genótipos avaliados, a abscisão caracterizouse como um fenômeno induzido, pois o patógeno aparentemente não está presente na zona de abscisão, e o processo de indução pode ser resultante da patogênese (Reuveni et al., 1974). Duas hipóteses podem ser formuladas com relação à queda de folhas em C. baccatum, C. chinense e C. frutescens: uma é que são extremamente sensíveis a qualquer tipo de estresse (patógeno, temperatura, umidade). A outra é de que a perda de folhas seja uma característica fenológica intrínseca quando inicia-se o florescimento e/ou frutificação.

\section{Avaliação em casa de vegetação}

Os resultados em plantas cultivadas em canteiros de casa de vegetação sob infestação natural foram análogos àqueles obtidos em telado. Dos genótipos testados $56 \%$ foram AS; 16\% MS; 11\% MR; 9\% R e 8\% AR (Tabela 4). Essas porcentagens foram semelhantes àquelas relatadas por Souza \& Café Filho (2003), que examinaram uma amostra diferente de 
162 genótipos de Capsicum spp.

Todos os genótipos classificados como AS pertencem à espécie C. annuum, o que representa mais de $68 \%$ dos acessos desta espécie. Dos genótipos de C. annuum restantes, cerca de $20 \%$ foram MS, sete genótipos foram MR, um genótipo foi R e um genótipo foi considerado AR. Dentre os genótipos de C. baccatum, um foi AR, três foram R e apenas um foi MR. Nenhum representante de C. baccatum foi classificado como MS ou AS. Capsicum frutescens teve quatro genótipos AR. Capsicum chinense teve um genótipo AR, cinco R e dois MR.

Ao correlacionar-se o número de dias após o transplante para o início do florescimento com os graus de resistência, mais uma vez obteve-se baixa, porém significativa, correlação $\left(\mathrm{r}^{* *}=-0,4419\right)$, corroborando a correlação entre precocidade no florescimento e susceptibilidade.

\section{Comparação das avaliações em telado e casa de vegetação}

A avaliação dos genótipos em dois ambientes distintos mostrou que o agrupamento geral dos genótipos permaneceu praticamente inalterado, mesmo com condições de infecção e desenvolvimento da hospedeira e da doença peculiares a cada ambiente. As pequenas variações no grau de resistência ao oídio nos dois ambientes sugerem a presença de genes maiores e menores controlando esta característica em Capsicum spp., com pequenas contribuições dos genes menores.

O efeito das condições climáticas distintas prevalentes em cada avaliação sobre genes menores pode explicar as pequenas flutuações observadas no comportamento de resistência e/ou susceptibilidade ao oídio, uma vez que a infecção e a colonização no hospedeiro são fortemente influenciadas pelas condições ambientais. Aparentemente as condições de infecção e de crescimento do hospedeiro em casa de vegetação foram menos favoráveis ao oídio. Daubèze et al. (1995) creditaram essas pequenas diferenças a fatores genéticos que envolvem a resistência, sendo amplamente influenciados pelas condições de infecção e ambientais.

Ao correlacionar valores de $\mathrm{AACPD}_{\%}, \mathrm{AACPD}_{\mathrm{SPOR}}$, $\mathrm{AACPD}_{\mathrm{PropF}_{0}}$ e $A A C P D_{\text {Id }}$ de genótipos avaliados em telado e casa de vegetação, obteve-se correlação positiva entre as reações nos dois locais de cultivo, ou seja, o comportamento quanto à resistência dos genótipos nos dois experimentos foi bastante similar (Figura 2).

Em ambas as condições de cultivo, C. annuum apresentou os mais baixos níveis de resistência à $O$. taurica, resultado semelhante ao relatado por Ullasa et al. (1981), Kounovski et al. (1985), Desphande et al. (1985), Bidari et al . (1985), Anand et al. (1987) e Souza \& Café Filho (2003). Uma das causas dessa menor resistência ao oídio pode ser a domesticação de $C$. annuum, onde os genes que conferem resistência foram perdidos durante o processo de seleção (Reifschneider et al., 2000). Isto pode ser observado no fato das fontes de resistência em pimentas serem representadas por espécies menos domesticadas (C. baccatum, $C$. chinense e $C$. frutescens), bem menos difundidas para o cultivo de larga escala do que o pimentão. A identificação de genótipos de $C$. annuum (espécie mais domesticada) resistentes ao oídio é um
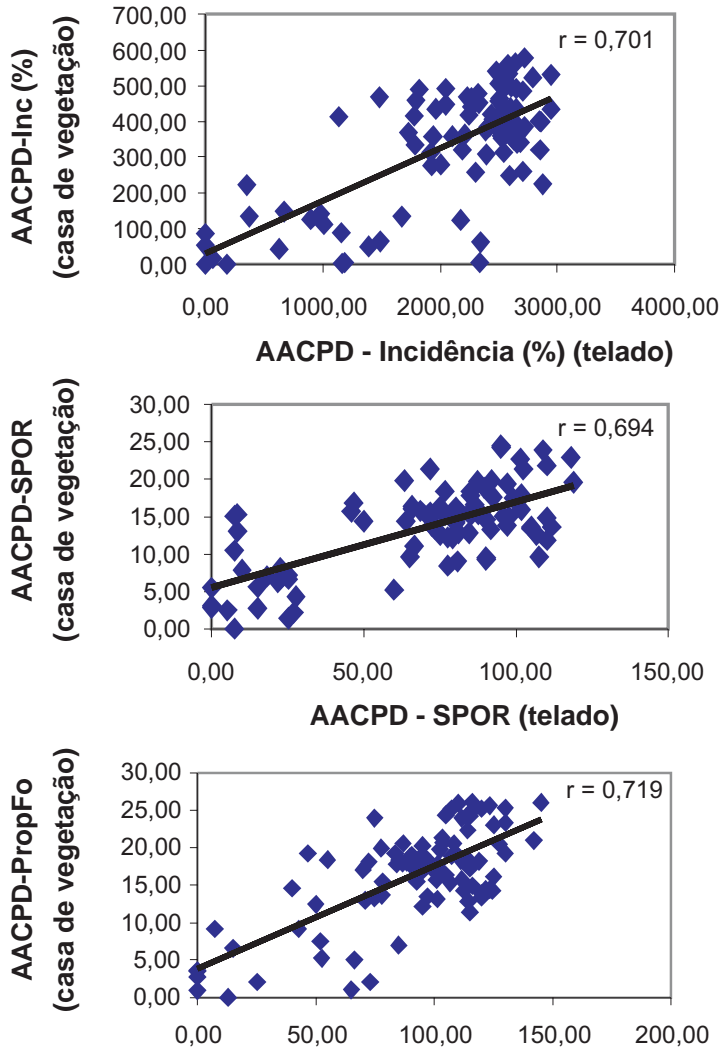

AACPD - PropFo (telado)

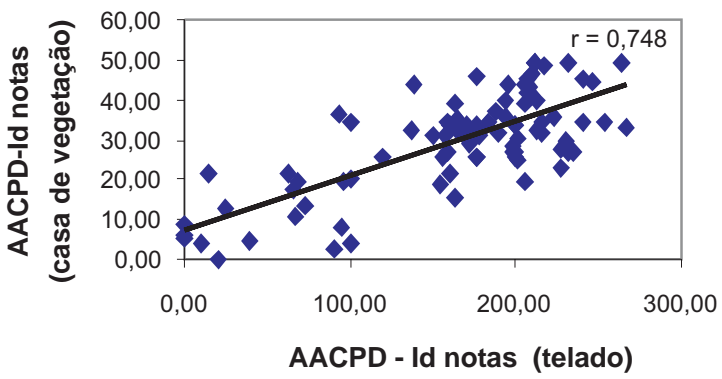

FIG. 2 - Correlação entre os valores de áreas abaixo da curva de progresso da doença em telado e casa de vegetação, medidos através das variáveis incidência (Inc.\%), índice de esporulação (SPOR), severidade de folhas (PropFo) e intensidade total da doença (Id-notas).

advento altamente vantajoso devido a maior facilidade de cruzamentos entre os mesmos.

As melhores fontes de resistência dentre os genótipos avaliados do germoplasma da Embrapa Hortaliças selecionados em telado e casa de vegetação são representadas por espécies de C. annuum (CNPH 1424); C. baccatum (CNPH 39, CNPH 161 e CNPH 672); C. frutescens (CNPH 596, CNPH 597 e CNPH 579) e C. chinense (CNPH 55, CNPH 289, CNPH 434 e CNPH 600). Estes genótipos são distintos daqueles previamente identificados por Daubèze et al. (1995), Souza \& Café Filho (2003) e Ullasa et al. (1981) que avaliaram diferentes amostras do germoplasma do gênero Capsicum. Finalmente, a avaliação repetida em dois ambientes serve para validar o processo de seleção de resistência em vasos em telado, pois esses genótipos 
Estabilidade da resistência de Capsicum spp. ao oídio em...

serão eficientes também em condições similares àquelas do cultivo protegido.

\section{AGRADECIMENTOS}

O trabalho foi realizado com apoio financeiro parcial do PRODETAB/Banco Mundial e do Conselho de Desenvolvimento Científico e Tecnológico-CNPq.

\section{REFERÊNCIAS BIBLIOGRÁFICAS}

ALLAGUI, B. Evaluation of pepper genotypes for Leveillula taurica Lev. (Arn.) resistance in Tunisia. Capsicum and Eggplant Newsletter 12:81-82. 1993.

ALLAGUI, B., PALLOIX, A. \& HAMZA, N. Resitance du piment (Capsicum sp.) à Leveillula taurica: evolution de l'épidemie avec la croissance des plantes. Phytopath. Mediterranea 34:143-148, 1995.

ANAND, N., DESPHANDE, A.A. \& SRIDHART, T.S. Resistance to powdery mildew in a accession of Capsicum frutescens and its inheritance pattern. Capsicum Newsletter 6:77-78. 1987.

BIDARI, V.B., BHAT, B.N. \& HEGDE, R.K. Reaction of different genotypes of chili against Leveillula taurica (Lèv) Arn. Indian Journal Agricultural Science 55:557-559. 1985.

BOITEUX, L.S., SANTOS, J.R.M. \& LOPES, C.A. First record of powdery mildew of sweet-pepper Capsicum annuum incited by Leveillula taurica in Brazil. Fitopatologia Brasileira 19(Suplemento):304. 1994. (Resumo)

BRAUN, U. The genus Leveillula - A preliminary study. Nova Hedwigia 32:565-583. 1980.

CAFÉ FILHO, A.C., COELHO, M.V.S. \& SOUZA, V.L. Oídios em hortaliças In: Stadinik, M.J. \& Rivera, M.C. (Eds.) Oídios. Jaguariúna/SP. Embrapa Meio Ambiente. 2001. pp.285-302.

DAUBÈZE, A.M., HENNARD, J.W. \& PALLOIX, A. Resistance to Leveillula taurica in pepper (Capsicum annuum) is oligogenically controlled and stable in Mediterranean regions. Plant Breeding 114:327-332. 1995.

DAUBÈZE, A.M., POCHARD, E. \& PALLOIX, A. Inheritance of resistance to Leveillula taurica and relation to other phenotypic characters in the haplodiploid progeny issued from an African pepper line. Proceeding, VII Meeting on Genetics and Breeding on Capsicum and Eggplant, Kragujevac, Yuguslavia, 1989. pp.229-232.

DESPHANDE, A.A., ANAND, N., PATHAK, C.S. \& SRIDHAR, T.S. New sources of powdery mildew resistance in Capsicum species. Capsicum Newsletter 4:75-76. 1985.

FERNÁNDEZ, M.C. Leveillula taurica (Lév.) Arn. a new organism causes of powdery mildew in artichoke. Agricultura Técnica 50:386389. 1990.
KARAKAYAMA, A. Leveillula taurica on Onobryches viciifolia in Turkey. Mycotaxon 66:359-361. 1998.

KOUNOVSKI, J.S., TODOROVA, J.J. \& STOIMENOVA, A.E.S. Capsicum chinense source of resistance to Leveillula solanacearum f. sp. capsici Gol. and tobacco mosaic virus. Capsicum Newsletter 4:68-69. 1985.

MOLOT, P.M. \& LECOQ, H. Les oidium des Cucurbitacées. I. Données bibliographiques Travaux préliminaires. Agronomie 6:355362.1986.

MUNEEM, K.C., VERMA, S.K. \& PANT, K.C. Performance of some chillies against leaf spot, powdery mildew and fruit rot in Kumaon Hills. Indian Phytopathology 47:206. 1994.

PALTI, J. Biological characteristic, distribution and control of Leveillula taurica (Lèv) Arn. Phytopathol. Mediterranea 10:139-153. 1971.

PALTI, J. The Leveillula mildews. The Botanical Review 54:423535. 1988.

PAZ LIMA, M.L. \& CAFÉ FILHO, A.C. Seleção de genótipos de Capsicum spp. resistentes à infecção por oídio. Horticultura Brasileira 19:287. 2001. (Resumo)

REIFSCHNEIDER, F.J.B, RIBEIRO, C.S.C. \& LOPES, C.A. Pepper production and breeding in Brazil, and a word on eggplants. Capsicum and Eggplant Newsletter 17:13-18. 1998.

REIFSCHNEIDER, F.J.B. (Ed.) Capsicum, pimentas e pimentões no Brasil. Ed. Embrapa, Brasília/DF, 2000.

REUVENI, R. \& ROTEM, J. Epidemics of Leveillula taurica on tomatoes and peppers as affected by the conditions of humidity. Phytopathologische Zeitschrift 76:153-157. 1973.

REUVENI, R., PERL, M. \& ROTEM, J. The effect of Leveillula taurica on leaf abscission in peppers. Phytopathologische Zeitschrift. 80:79-84. 1974.

SHANER, G. \& FINNEY, R.E. The effect of nitrogen fertilization on the expression of slow-mildewing resistance in Knox wheat. Phytopathology 67:1051-1056. 1977.

SHIFRISS, C., PILOWSKY, M. \& ZACKS, J.M. Resistance to Leveillula taurica mildew (=Oidiopsis taurica) in Capsicum annuum. Phytoparasitica 20:279-283.1992.

SOUZA,V.L. \& CAFÉ FILHO, A.C. Resistance to Leveillula taurica in genus Capsicum. Plant Pathology 52:613-619 2003.

THOMSOM, S. \& JONES, W.B. An epiphytotic of Leveillula taurica on tomatoes in Utah. Plant Disease 65:518-519. 1981.

ULLASA, B.A.; RAWAL, R.D.; SINGH, D.P. \& JOSHI, M.C. Reaction of sweet pepper genotypes to anthracnose, cercospora leaf spot, and powdery mildew. Plant Disease 65:600-601. 1981.

VAN DER PLANK, J.E. Plant Diseases: Epidemics and Control. Academic Press. New York, NY, 1963.

ZAR, J. H. Biostatistical Analysis (4th ed.). Prentice-Hall, Inc., Englewood Cliffs, New Jersey. 1998. 